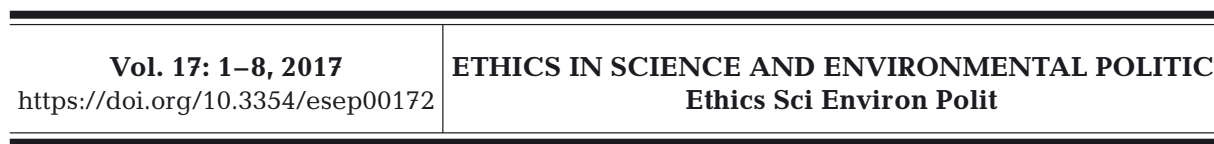

Contribution to the Theme Section 'The ethics and practice of openness in life sciences data'
Published April 7

\title{
Open access revolutions
}

\author{
Ferdinando Boero' ${ }^{1,2, *}$ \\ ${ }^{1}$ University of Salento, DiSTeBA, Via P. le Lecce-Monteroni, 73100 Lecce, Italy \\ ${ }^{2}$ CNR-ISMAR, Via De Marini 6, 16149 Genoa, Italy
}

\begin{abstract}
Open Access (OA) databases and publications are revolutionizing the storage and communication of scientific results. OA databases of physical and chemical measurements have been available for a long time, thanks to automated procedures of data acquisition and processing, whereas this is still not possible with marine biodiversity data. The pay-per-view policy is being replaced by the pay-to-be-viewed policy, with authors paying the expenses of the OA to their work. The ethical side of OA is clear: the whole world should be able to profit from new knowledge, not only those who can afford it, especially because research is often paid with public funds. Since funding agencies increasingly ask their beneficiaries to publish their work with OA, OA journals with unclear quality standards are proliferating, and some are publishing unreliable results. Private companies, with either pay-per-view (Scopus, The Web of Knowledge) or OA (Google Scholar) policies, rate the outputs of research. Funding agencies (e.g. Wellcome) are experimenting a further development of the OA strategy, launching OA platforms that they manage directly, with signed peer reviews. Similar experiments are being conducted with databases of raw data. Public funding agencies should also fully embrace this policy. OA policies are still developing, but the route towards a more democratic fashion of making the results of scientific research openly available is mapped out.
\end{abstract}

KEY WORDS: Open Access $\cdot$ Data Banks $\cdot$ Science and technology $\cdot$ Publication policy $\cdot$ Science rating

\section{INTRODUCTION: BAZAARS AND CATHEDRALS}

Raymond (1999) proposed the metaphor 'cathedral vs. bazaar' to distinguish centralized and projectbased ways of conducting research (the cathedral) from open-source approaches (the bazaar) that involve the collaboration of innumerable persons who work while making their own results available to the rest of the community. Raymond (1999) compared the development of the open-source Linux software as opposed to the software developed by 'closed' companies. Linux is developed as a 'bazaar': all users have their little shop, they openly interact with their customers and with each other, the information spreads through a network of relationships, and the business grows as a real web. In contrast, the 'cathedral' has a single brain (the architect) who uses a multitude of collaborators aimed at realizing a single, monumental

*Corresponding author: boero@unisalento.it project. It is not by chance that real bazaars are horizontal, whereas real cathedrals are vertical.

Raymond (1999) obviously prefers bazaars, an opinion shared by Woelfle et al. (2011) who argued that 'Open science is a research accelerator' while examining the development of a drug by a consortium involving industry and academia, both working on an open source basis. However, if open science has lots of advantages, why is science still so 'closed'?

\section{WHO OWNS THE DATA?}

\section{Reasons for data sequestration}

The recognition of intellectual property, and eventually the obtainment of revenue from it (in either monetary or reputational terms), is the main obstacle

() The author 2017. Open Access under Creative Commons by Attribution Licence. Use, distribution and reproduction are unrestricted. Authors and original publication must be credited. 
to openness in science. Researchers do not like to share their data for a very simple reason: open data of any kind become valuable only if they are used, and it is not necessarily the person who gathered them who is going to do so. It is in the interest of the authors that their published work spreads freely throughout the scientific community, so they prefer the Open Access (OA) option, but scientists are wary of making their raw data available. Publications contain elaborations of data, but the whole dataset usually remains unpublished.

When data do not lead to a publication, scientists often refrain from sharing them with their peers in an open platform, keeping them in their personal archives. McClenachan et al. (2012) discussed the importance of old data, including those they retrieved in personal archives of retired scientists, to set up conservation measures. The fear of being 'scooped' afflicts many scientists who are convinced that they are harboring treasures in their folders. Data sequestration in personal archives is quite common.

The main obstacles to open science, thus, reside in the fear of lack of recognition for the importance of one's own data, and fear that competitors will use them to publish papers without having had to 'dig out all the data': I did the work and they published their papers! The first thing that comes to mind is: So why don't you publish your paper with your data? The reason is simple: a dataset often acquires importance only if it is linked to other datasets. A single person can rarely build up a meaningful dataset, without tapping into the research of other scientists. For example, Rivetti et al. (2014) coupled physical data extracted from OA databases with data on mass mortalities of marine invertebrates, showing the link between these catastrophic events and the deepening of the summer thermocline. This is the 'bazaar' attitude, whereas those who remain closed in their 'cathedral' might run the risk of oblivion with regard to their knowledge, sequestered in their computer.

Moreover, the way research is supported requires scientists to apply for grants on a competitive basis. The efforts dedicated to writing grant proposals are increasingly high, and the time spent in doing so is often wasted, due to high chances of failure (Herbert et al. 2013). The pressure to obtain new grants might prevent researchers from publishing the results of previous grants: once the obligation of submitting reports has been fulfilled, time is invested in preparing new grants, and the data from previous projects might be published only in part, the rest being buried in personal archives.

\section{Who is sharing the data?}

Data sequestration is not the rule, however, and the tendency towards open data accessibility is becoming the norm in fields that involve the use of machines to obtain data. GenBank (Benson et al. 2013) is an OA database in which genetic sequences of species, extracted by PCR, are deposited and made available to the scientific community. Scientists can deposit sequences in GenBank and profit from the sequences of their peers: you give one, and receive one million in exchange. The field of physical oceanography is undergoing the same process (Hesse et al. 1993) with the sprouting of databases that contain essential data on the physical features of the oceans, usually extracted with automated systems. The same tendency is now becoming evident for marine biodiversity (Costello \& Vanden Berghe 2006) and fish (Froese \& Pauly 2016), even though massive collection of biological data is still very difficult. As yet, automated machines cannot tell us much about biodiversity and ecosystem functioning, and data production requires the intervention of knowledgeable humans. Costello et al. (2013) argued that, with proper investment, the inventory of biodiversity, with the naming of all species, is a feasible enterprise. To do so, however, the work of taxonomists is needed and, since taxonomy is underfunded (Boero 2010), taxonomists tend not to share their work, due to a lack of factual recognition.

The use of molecular approaches has been proposed as a solution for the inventory of biodiversity, hindered by the taxonomic impediment (Godfray 2007). 'Species' are sequenced and given a barcode. The barcode is deposited in GenBank and is freely available online. Once this information is stored in a database, species identification is easy: biological material is sequenced and newly obtained sequences are compared with those already available online, assigned to a given species; thus, a machine can do the job of a taxonomist. Although metagenomics can help in the identification of already described species, it does not help much in describing new species, since only sequences are known: the knowledge of phenotypes remains obscure.

\section{Information is not knowledge}

GenBank, and Godfray's (2007) assumption that metagenomics, using the OA GenBank, can replace taxonomy in identifying specimens, is a good example of freely available information that might not 
promote the advancement of knowledge, but instead perpetuate mistakes. Even though phenotypic approaches are being considered as useless, as Godfray (2007) claimed, to genetically label a species and deposit its sequence in OA GenBank, geneticists assign specimens to nominal species based on phenotype analysis (i.e. with traditional taxonomy) and then sequence them. If the sequenced phenotype is wrongly assigned to a nominal species (due to lack of taxonomic expertise), the deposited sequence becomes the (wrong) reference for that nominal species.

Information based on poor knowledge, once spread throughout the internet with the power of OA, can lead to the perpetuation of mistakes, giving the impression that science can be replaced by technology (de Carvalho et al. 2007). Validation of data is therefore essential to make open science reliable. Identifications are also not reliable with traditional tools, since experienced taxonomists often quarrel about species identities according to different views of what a species is. Once incorrect information is crystallized in the open space of a database, however, its handiness coupled with the illusion of the power of genetic approaches encourages people to believe that it is valid. The integration of phenotypic and genotypic approaches is the only solution to this conundrum (Boero \& Bernardi 2014). Taxonomists will probably become more generous with their data when they receive proper recognition for their work.

\section{The data deluge}

The risk that huge databases, instead of being a tool for doing research, become the aim of research is concrete. The infrastructures that store them are becoming larger and larger, and information and communication technology (ICT) engineers are employed to design their architecture and to maintain them. The data are accumulated and lead to what Baraniuk (2011) called the 'data deluge'.

The running costs of huge databases likewise require huge investments, absorbing most of the resources dedicated to research, with the paradox that the money invested in the development of a science (with the expectation of new knowledge production) is diverted into technological development aimed at accumulating and spreading information that will not be used properly.

Boero (2010) warned that, in a period of huge investments to study biodiversity, the basic science of species description (taxonomy) is in distress. Boero
(2005) listed a long series of EU projects aimed at providing services to taxonomy, whereas not a single project is dedicated to taxonomy per se. The tools to do something are made available, but then there is no support to use them to actually do what they should be used for. The risk of this attitude resides in the performance of science being constrained by the available tools and not by the pressure of testing new ideas (Dyson 2012).

\section{Data owning}

Scientists usually work with financial support from funding agencies to realize projects. The results of the projects are delivered in the form of reports, even though funding agencies are increasingly asking for OA publication, an issue that will be treated later in this article. The raw data that lead to published articles are the basic knowledge that should be available to everybody, in order to evaluate the reliability of scientific papers by comparing the declared outcomes with the available data. Some journals publish online appendixes with the datasets on which articles are based, but these datasets are not organized into a single platform, and are available in a fragmented fashion. Sometimes, data are simply lost, for example because the computers in which they were stored are stolen (Berg 2016).

Long-term observation series (Britten et al. 2014, Boero et al. 2015) and the coupling of physical with biological data (Rivetti et al. 2014) can promote the understanding of global change by matching the change of physical features with corresponding changes in biodiversity expression. Although databases with physical, chemical, and biogeochemical data are quite widespread, it is difficult to find reliable databases about biodiversity. The standardization of data is still rather primitive and there is no agreement, even on basic categories such as habitats (Fraschetti et al. 2008).

'Physics envy' (Egler 1986) induced biologists and ecologists to abandon natural history with the aim of transforming their 'descriptive' sciences into 'predictive' ones (like physics) (Ricklefs 2012, Boero 2015a), but it is very difficult to transform complex data into the format of simple ones. The result is the above mentioned data sequestration by those who extracted them, due to the impossibility of using them in isolation from similar datasets.

These data, however, belong to the funding agencies, whose duty should be to make them publicly available. The calls for projects should specify very 
carefully the format of data, and in Europe this is done with the INSPIRE protocol. These data should then be stored in a single OA database, run by the funding agencies. This would boost biological research, allowing for deeper analyses of the conditions of biodiversity and ecosystem functioning. Some action is being undertaken in this direction, but the space for improvement is still enormous. Moreover, if data are not made openly available, they might be 'sold' as 'new' to different funding agencies.

\section{OPEN JOURNALS AND INFORMATION PLATFORMS}

\section{From open data to open publications}

OA data banks are very important as a source of 'raw' material. These data acquire meaning when they are analyzed in order to answer a particular question. The problem of the already mentioned data deluge (Baraniuk 2011) is that all of these data are often not used so as to express their whole heuristic potential. Data analyses usually become part of publications. A database is a tool, not a scientific result.

Funding agencies are increasingly asking their beneficiaries to publish their results in OA journals, in order to make them freely available to the scientific community. In this way, funding agencies demonstrate the impact of their support of science and democracy, since all can check the outcomes of the investment of public money in research. This trend is somehow influencing the industry of science publishing.

\section{The industry of scientific publication}

The publication of scientific data is very profitable, especially because it generally relies on unpaid work. The editorial board, the advisory board, the reviewers, and the authors, in fact, work for free. Editors-in-chief are sometimes paid, but in many cases they are not. Authors are often asked to contribute to publishing costs and historically were offered the option to buy reprints, a market that has vanished relatively recently due to the practice of distributing electronic files (e.g. PDFs), instead of reprints. By paying journal subscriptions, the libraries of scientific institutions pay to have access to the work of their own associates and of their col- leagues throughout the world. The scientific community is expected to pay for everything related to its own research, finding the financial support to perform it, and to work for free for publishing houses as authors, reviewers, and editors, whereas publishing houses cover just the costs of producing the journal, while gaining by selling it to those who work for free for them. In the past, the journals were printed on paper and shipped to subscribers, but this practice is being abandoned since libraries explode with the back issues that, for many journals, are no longer relevant after a short time. Journals are increasingly abandoning printed versions and are available online only. They have all back issues on their web site and, together, these web pages make up the largest, albeit virtual, library on the planet.

The access to scientific publications through the web is dramatically reducing publication costs, since there are no charges for printing and shipping the issues. This opens wide avenues for OA to scientific publications. Subscriptions to non-OA journals are extremely expensive, and only a few institutes can afford them, preventing emerging countries from having access to knowledge. The idea of OA journals is therefore timely and ethically right. The paradigm shift, then, resides in the authors paying the publication fees with their research money, and in most projects the budget envisages funds dedicated to dissemination of results, so as to cover publication expenses. The practice of open journals thus seems not to have any negative effect, since it makes the results of scientific research accessible to the whole world.

\section{The business of open journals}

This new trend has led to the sprouting of new OA journals that offer their services to the scientific community. Among others, Butler (2013) has argued that many of these journals are based on mere business interests and that they publish all submitted articles, as long as the authors pay the required fees. Many researchers receive offers to join editorial boards of new OA journals and are asked to submit their articles to them.

Bohannon (2013) submitted a clearly (and intentionally) flawed article to a host of OA journals, and in most cases, the article was accepted (as long as expenses were paid). Leading scientific journals such as Science, which published Bohannon's paper, serve their own interests in unmasking the unfair competi- 
tion of OA journals. Bohannon (2013) reported that only PLOS ONE, one of the main OA journals, correctly reviewed his fake submission and rejected it with substantial criticism.

\section{Compromises}

Many traditional journals are now offering the OA option. In this case, the authors pay a fee and, on the web site of the journal, their article is freely accessible to readers who do not subscribe to the journal. In this case, the journals continue to charge for subscriptions.

The authors of articles published in non-OA journals receive a PDF of their article and can ship it to those who ask for it. The email address of the authors is clearly stated on the journal's web site and, in this way, those who are interested in the article can request a PDF directly from the corresponding author. Research Gate and similar platforms allow their subscribers (with no fee) to upload the PDFs of their articles, and the other subscribers can freely download them. In this way, the PDF request to the author is skipped and papers are available through an OA platform. Apparently, publishers tolerate this practice.

Some sites based in countries that do not recognize copyright rules offer free downloads of articles and books covered by copyright. This usually does not affect the authors, who do not receive any royalties ensuing from the sale of their work; however, it does effect the publishers.

\section{The advantage of $\mathrm{OA}$ to authors}

The payment of a fee to publish in an OA journal is surely a disadvantage for authors. Openness, however, allows more people to access the article and increases the chances of citations. The status of researchers is linked to the number of citations that their work attracts: the more an article is accessible, the higher the chances of citation. In a bibliographic search in the internet, in fact, authors tend to consult papers that are available at a click. OA articles are immediately available, whereas those published in non-open journals have higher chances of not being consulted (and cited). Hence, OA articles have higher chances of being cited than papers that can only be consulted upon payment of a fee. The increased chance of being cited due to free availability of their articles can increase the Impact Factor of
OA journals, with a further positive return for the OA policy.

\section{ISI WoK and Scopus}

Thomson Science, through the Institution of Scientific Information's Web of Knowledge (ISI WoK), ranks journals according to a series of metrics, the Impact Factor (IF) being the most popular one, whereas other metrics, such as the Cited Half Life, are usually disregarded (Boero 2015b). Scopus, the other leading platform that scores the performances of scientists, is owned by Elsevier, one of the major scientific publishers of the world; thus, a rating company is owned by one of the rated companies.

The IF of a journal is based on the number of citations that its articles attract in a monitored period, usually 3 to 5 yr after publication. McVeigh (2004) studied the IF trends for OA journals in citation databases. The enormous number of new OA journals, however, makes these scores rapidly obsolete. Moreover, journals sometimes alter their metrics in a nontransparent fashion, thereby instilling distrust in the way scientific literature is rated (Rossner et al. 2007).

Both the ISI WoK and Scopus require the payment of a subscription to be accessed; however, OA is also gaining momentum in this field.

\section{Google Scholar}

Google Scholar produces Scholar Citations, an OA initiative that shows the main bibliometric scores of researchers. Furthermore, researchers can build up a page that contains all the scientific products, along with the number of citations of each product and standard metrics such as the $h$-index (Hirsch index). This information can be obtained for free, as Scholar Citations is OA. It covers publications in scientific journals, similar to ISI WoK and Scopus, but also all other documents that are deposited on the Web, such as PhD theses and grey literature, books, and all other forms of scientific communication. Scopus and WoK usually lead to lower scores than Scholar Citations; the positive bias of Scholar Citations, however, is common to all researchers, as is the negative bias of the other 2 platforms. Thus, the results of each platform allow for comparisons among scientists (Pauly \& Stergiou 2005). The problem of homonymies affects all 3 platforms, but Scholar allows 'cleaning' the author's page from papers by homonymous authors. This is left to the 
individual researcher, who has to build up his own page, leading to a transparent product where all consultants with an expertise in the field can understand how reliable these data are. The OA of Scholar Citations, and the possibility of inserting addresses near the authors' names, as well as a series of key words, allows immediate visualization of the production of an institution (if all members have their own page) and to compare an author with other members of the scientific community that describe their own expertise with the same key words.

In a period of evaluation of scientists and scientific institutes, such an instrument is transparent and free of charge, and allows for simple and fast comparisons of some metrics (Pauly \& Stergiou 2005). The use of bibliometry to compare scientists, however, is currently controversial (e.g. Lawrence \& Garwood 2011, Fischer et al. 2012, Casadevall et al. 2016).

\section{Comparing the platforms}

Pauly \& Stergiou (2005) compared the ISI WoK and Scopus and found comparable data. However, a search for my own name in the 3 platforms in October 2016 led to different outcomes. The ISI WoK yielded 179 articles, with an $\mathrm{H}$ index of 34. Scopus listed 194 items and an H index of 37, and the My Scholar Citations page listed 369 entries, and an $\mathrm{H}$ index of 47.

A monograph on the Hydrozoa (Bouillon et al. 2006), which I co-authored, was not covered in WoK, and Scopus listed it as a 'secondary document', probably because it is not published in a journal that is formally recognized by the platform. In Scholar, the same monograph has 206 citations and represents a substantial contribution to my scientific profile. Hence, the 2 non-open platforms fail to report products that substantially add to my contribution to knowledge, whereas they are present in the OA platform. Strangely, national agencies often evaluate researchers from the data in Scopus and WoK, and disregard Scholar Citations (F. Boero pers. obs.).

\section{Open peer review}

Faculty of 1000 (F1000) launched the OA platform F1000 Research (https://f1000research.com), with a policy that involves immediate publication of papers, subjecting them to subsequent peer review by non-anonymous reviewers. The reviews are published in conjunction with the article, as soon as they come in. The authors are asked to modify the text accordingly, until it satisfies the requests of the reviewers. If the review is negative, the article is withdrawn. In this case, not only is the article OA, but the reviews are also signed and made explicit, and the process leading to the final acceptance or rejection of the paper is completely open. This puts responsibility not only on the authors but also on the reviewers.

Wellcome Open Research (WOR: http://wellcome openresearch.org), based on the same procedure of F1000 Research, is a further step in OA and open review publication processes. WOR, in fact, is open to all researchers funded by Wellcome. This new avenue satisfies the funding agencies that increasingly require the beneficiaries of their support to publish OA articles deriving from their work.

The direct involvement of funding agencies in the dissemination of the results of what has been found with their financial help is an alternative route to that of standard journals - either of traditional nature (pay to view) or operating OA (pay to be viewed) - and, if followed by national funding agencies, might trigger a complete revolution in the field of scientific publication. It is reasonable, in fact, that funding agencies directly publish the outcomes of the research they support, evaluating the success of projects through the peer review of the papers submitted to their platforms, where the raw data are also stored. In this way, the databases would contain both the data and their elaboration, and would be under public control. Besides Wellcome, other funding agencies and institutes are producing OA platforms that do not require a fee from the authors (Tsikliras \& Stergiou 2013); this trend is expanding.

\section{CONCLUSIONS}

Democratic science requires that research performed with public money is accessible to everyone, and OA of both data and their elaboration in scientific papers satisfies this ethical demand. Non-public funding agencies, such as Wellcome, are also embracing this view.

If 'what to do' is becoming increasingly clear, and OA is increasingly gaining momentum, 'how to do it' is not completely clear yet. F1000 and Wellcome are triggering a new way of OA publication, with platforms that publish results at the expenses of the funding agencies. This new procedure is very promising and might involve established journals, 
in order to push them into the same policy: funding agencies might directly pay established journals to publish OA results deriving from work paid for by the agencies. As an alternative, funding agencies might produce their own journals in which to publish the results of the research they support. This might bypass the production of project reports, an intermediate step that burdens the work of researchers. Projects should be evaluated on the basis of the published results, and not on the basis of submitted reports. The open peer review of articles is a further step in a completely transparent publication process. The databases associated with each article should then be merged into global databases.

OA of both data and their elaboration is changing the way scientific results are shared throughout the scientific community, hopefully leading to truly democratic science. The openness of science has started, many funding agencies are requiring it and the new path is taken: future knowledge will be increasingly openly accessible.

Acknowledgements. This work was supported by the following: the Ministero dell'Università e della Ricerca Scientifica e Tecnologica (PRIN projects); the Flagship project RITMARE; the European Commission Seventh Framework Programme (FP7) projects 'Vectors of Change in Oceans and Seas Marine Life, Impact on Economic Sectors' (VECTORS), 'Towards coast to coast networks of marine protected areas (from the shore to the high and deep sea), coupled with seabased wind energy potential' (COCONET), and 'Policy-oriented marine Environmental Research in the Southern European Seas' (PERSEUS); the European Commission Blue Growth projects 'Marine Ecosystem Restoration in changing European Seas' (MERCES), and 'European Virtual Environment for Research - Earth Science Themes: a solution' (EVER-EST). I thank Kostas Stergiou for having invited me to write this paper.

\section{LITERATURE CITED}

Baraniuk RG (2011) More is less: signal processing and the data deluge. Science 331:717-719

Benson DA, Cavanaough M, Clark K, Karsch-Mizrachi I, Lipman DJ, Ostell J, Sayers EW (2013) GenBank. Nucleic Acids Res 41(Database Issue):D36-D42

Berg J (2016) Editorial expression of concern. Science 354: 1242

Boero F (2005) Lots of biodiversity research services... but for whom? MaRBEF Newsl 3:27

Boero F (2010) The study of species in the era of biodiversity: a tale of stupidity. Diversity (Basel) 2:115-126

Boero F (2015a) From Darwin's Origin of Species towards a theory of natural history. F1000Prime Rep7:49

Boero F (2015b) Scientists can be free, but only once they are tenured. Ethics Sci Environ Polit 15:63-69
Boero F, Bernardi G (2014) Phenotypic vs genotypic approaches to biodiversity, from conflict to alliance. Mar Genomics 17:63-64

Boero F, Kraberg AC, Krause G, Wiltshire KH (2015) Time is an affliction: why ecology cannot be as predictive as physics and why it needs time series. J Sea Res 101: 12-18

* Bohannon J (2013) Who's afraid of peer review? Science 342: 60-65

*Bouillon J, Medel MD, Pagès F, Gili JM, Boero F, Gravili C (2004) Fauna of the Mediterranean Hydrozoa. Sci Mar 68(Suppl 2):5-438

Bouillon J, Gravili C, Pagès F, Gili J-M, Boero F (2006) An Introduction to Hydrozoa. Mémoires du Muséum national d'Histoire naturelle, Vol. 194. Muséum National d'Histoire Naturelle, Paris

* Britten GL, Dowd M, Minto C, Ferretti F, Boero F, Lotze HK (2014) Predator decline leads to decreased stability in a coastal fish community. Ecol Lett 17:1518-1525

* Butler D (2013) The dark side of publishing. Nature 495: 433-435

* Casadevall A, Bertuzzi S, Buchmeier MJ, Davis RJ and others (2016) ASM journals eliminate impact factor information from journal websites. MBio 7:e01150-16

* Costello MJ, Vanden Berghe E (2006) 'Ocean biodiversity informatics': a new era in marine biology research and management. Mar Ecol Prog Ser 316:203-214

* Costello MJ, May RM, Stork NE (2013) Can we name Earth's species before they go extinct? Science 339:413-416

* de Carvalho MR, Bockmann FA, Amorim DS, Brandaõ CRF and others (2007) Taxonomic impediment or impediment to taxonomy? A commentary on systematics and the cybertaxonomic-automation paradigm. Evol Biol 34: 140-143

*Dyson FJ (2012) History of science. Is science mostly driven by ideas or by tools? Science 338:1426-1427

Egler FE (1986) 'Physics envy' in ecology. Bull Ecol Soc Am 67:233-235

Fischer J, Ritchie EG, Hanspach J (2012) Academia's obsession with quantity. Trends Ecol Evol 27:473-474

Fraschetti S, Terlizzi A, Boero F (2008) How many habitats are there in the sea (and where)? J Exp Mar Biol Ecol 366:109-115

Froese R, Pauly D (eds) (2016) FishBase. www.fishbase.org

Godfray HCJ (2007) Linnaeus in the information age. Nature 446:259-260

KHerbert DL, Barnett AG, Clarke P, Graves N (2013) On the time spent preparing grant proposals: an observational study of Australian researchers. BMJ Open 3:e002800

\%Hesse BW, Sproull LS, Kiesler SB, Walsh JP (1993) Returns to science: computer networks in oceanography. Commun ACM 36:90-101

Lawrence P, Garwood J (2011) The heart of research is sick. Lab Times 2:24-31

*McVeigh ME (2004) Open access journals in the ISI citation databases: analysis of impact factors and citation patterns. A citation study for Thompson Scientific. http://ip-science.thomsonreuters.com/m/pdfs/openaccess citations2.pdf

*McClenachan L, Ferretti F, Baum JK (2012) From archives to conservation: why historical data are needed to set baselines for marine animals and ecosystems. Conserv Lett 5: 349-359

Pauly D, Stergiou KI (2005) Equivalence of results from two citation analyses: Thomson ISI's Citation Index and 
Google's Scholar service. Ethics Sci Environ Polit 5: 33-35

Raymond E (1999) The cathedral and the bazaar. Know Techn Pol 12:23-49. https://link.springer.com/article/ 10.1007/s12130-999-1026-0

Ricklefs RE (2012) Naturalists, natural history, and the nature of biological diversity. Am Nat 179:423-435

Rivetti I, Fraschetti S, Lionello P, Zambianchi E, Boero F (2014) Global warming and mass mortalities of benthic

Editorial responsibility: Konstantinos Stergiou, Thessaloniki, Greece invertebrates in the Mediterranean Sea. PLOS ONE 9: e115655

Rossner M, Van Epps H, Hill E (2007) Show me the data. J Exp Med 204:3052-3053

Tsikliras AC, Stergiou KI (2013) What's on the (publication fee) menu, who pays the bill and what should be the venue? Mediterr Mar Sci 14:363-364

*Woelfle M, Olliaro P, Todd MH (2011) Open science is a research accelerator. Nat Chem 3:745-748

Submitted: November 16, 2016; Accepted: December 30, 2016

Proofs received from author(s): March 3, 2017 